\title{
Participatory futures research. Research or practice consulting?
}

\author{
Reinhold Popp
}

Received: 11 June 2013 / Accepted: 5 August 2013 / Published online: 20 September 2013

(C) The Author(s) 2013. This article is published with open access at Springerlink.com

\begin{abstract}
This article combines futures research with participatory practice research, whose methodical approaches such as "community participation", "community-based participatory research" and "participatory action research" not only proved to be significant in the prime age of action research in the 1970s, but these topics are growing research domains even today. Based on the current status of discussion about action research, this article presents the methodological principles and methodical specifics of a scientifically substantiated participatory futures research. Its most important principles are a) a clear role distribution between the actors of futures research on the one hand and practitioners in the respective action field of futures shaping on the other, b) visible orientation to quality factors of scientific study (that are appropriate for the object of study), c) transparency in terms of concrete research processes and research products and, based on this data, for feedback to the scientific system, as well as d) the involvement of participation-oriented researchers in the critical discourse of the scientific community. The term "research" should not be used until at least these quality factors for good research are fulfilled.
\end{abstract}

Keywords Participatory research $\cdot$ Action research $\cdot$ Futures research $\cdot$ Methodology $\cdot$ Quality criteria

\section{How scientific is participatory futures research?}

Futures research forms a very marginal part of the activities of universities and large research companies throughout Europe $[1, p 25]$. Several small companies working in the field of

R. Popp $(\bowtie)$

Salzburg University of Applied Sciences, Center for Futures Studies, Urstein Süd 1, 5412 Puch/Hallein, Austria

e-mail: Reinhold.popp@fh-salzburg.ac.at future-oriented corporate and policy consulting fill up this academic gap. These consultants mostly implement futureoriented communications, consulting and planning processes by an internal arrangement with commercial enterprises or even in public administration institutions (e.g., in ministries, etc.). Some representatives consider their services of participatory assistance in corporate foresight processes as participatory research [2, p 10]. Is this claim justified? Or should these services be defined as futures consulting, strategic planning or, at best, as "futures management" [3]?

At present, there is no answer to this question. Reports about these activities that could be scientifically evaluated are lacking - at least in German-speaking regions. Corporate foresight activities help prepare decision making processes in organisations, institutions or companies. Apparently, customers often do not want the transparency required for scientific review; therefore, contractors do not provide it. Furthermore, it should be checked if the coordinators of such projects are integrated into the quality-assuring system of the scientific community. Whether the so-called participatory futures research can actually be called "research" is therefore impossible to assess at the moment - due to lack of project reports that can be evaluated.

Hence, this article has to make do with outlining the criteria for participatory practice research in general and participatory futures research in particular. Based on the current status of discussion about action research, the methodological principles and methodical specifics of a scientifically substantiated participatory futures research are presented here.

With this in mind, the author of this article advocates

- a clear role distribution between the actors of futures research, i.e., the researchers, on the one hand, and practitioners in the respective action field of futures shaping on the other, 
- visible orientation to quality factors of scientific study (that are suitable for the object of study),

- more transparency in terms of concrete research processes and research products and, based on this data, for feedback to the scientific system, as well as

- the essential involvement of participation-oriented researchers in the critical discourse of the scientific community.

\section{Empirical research in the conflict between experiment and case study}

Fundamentally, empirical research has a relatively wide range of research strategies in the conflict area between experiment and case study. Considered individually, none of these strategies is better or worse as suggested in research-methodologically or research-methodically oriented discourses from time to time, for example, when the so-called qualitative research concepts are compared with the so-called quantitative concepts. On the contrary, the quality of selection of a research strategy must be assessed exclusively in view of the research task to be handled or the targeted research objective. Strategies or methods are only means to achieve this objective. Highquality research thus aligns the strategy or method to the research objective and to the object of research.

On the other hand, poor-quality research occurs when the research objective and the object of research are considered to be subordinate to the research strategy or method, irrespective of whether this cardinal error is made by researchers with qualitatively or quantitatively oriented methodical preferences.

Even the so-called quality factors for research processes, except for a few very general criteria that are applicable to all process types (e.g., transparency), can be defined only in relation to the respective research tasks or objectives and objects of research.

Based on the principle of "objective and object suitability", the socio-scientific research allows us to make a rough distinction between variable-manipulative and variableconfigurative strategies - as illustrated by the diagram below (see Fig. 1, modelled on Schaffer [4]).

Variable-manipulative research strategy

The variable-manipulative research strategy that has been adopted from natural sciences is the right choice in the field of social sciences when the research objective is the production of generalised statements about the causal relations of the examined social action system in each case, derived from the researched cause-effect relations, as well as the production of general, future-oriented statements about concepts or methods for influencing the system.
This research strategy can be successful only if the constituent variables of the system, including the activities of the researcher, are strictly isolated and controlled (= variables manipulation) during the complete examination process. Variable-manipulative research strategies can be roughly categorised into experiments and statistical causal analyses.

It is generally known that experiments are conducted to find out the causal relations (= cause-effect) regarding the influence of independent (or extraneous) variables on the dependent (or endogenous) variables of the (action) system to be examined and to perhaps make prognostic statements.

This involves

- random selection of test persons,

- forming groups of equal or at least similar composition (= experimental group and control group),

- precise isolation of research-relevant variables, as well as

- controlling these variables throughout the experimental examination.

Lab experiments are accepted by the purists of empirical research as the only possible research strategy with which hypotheses about the cause-effect relations can be tested or falsified and after which perhaps prognoses can be made. Critics, on the other hand, stress the artificiality and thus the lack of object suitability of lab experiments when it comes to socio-scientifically relevant problems.

Quasi experiments: In this type of (field) experiment, the strict rules of condition control that are necessary for lab experiments are made lax to some extent, due to reasons pertaining to objective and object suitability. The most frequently occurring examples of this are the formation of a control group or groups only afterwards (ex post facto) and the relaxation of the principle of random selection of the test persons.

Statistical causal analyses are based on models, all of which, if possible, take into account the variables that are relevant for the structure and function of a system and which, like in the case of experiments, assume hypotheses about the causal explanations of changes in endogenous (or dependent) variables that are brought about by the extraneous (or independent) variables of this system. The appropriateness of these hypotheses is examined through a statistical causal analysis. A variety of tried and tested statistical methods are available for this.

Variable-configurative research strategy

The prerequisite of complete variable-control, which is indispensable for the variable-manipulative research strategy, cannot obviously be realised if a research project aims at scientific analysis of complex, multifactorial and dynamically and flexibly changing social action or practice. This often applies to 
Variables manipulation

Main objective:

Production of generalised statements about causal relations of action systems as well as deduction of methodical suggestions for the system impact
Variables configuration

Main objective:

Multifactorial analysis of individual, complex and dynamic action systems as well as practical innovation in the method of system impact

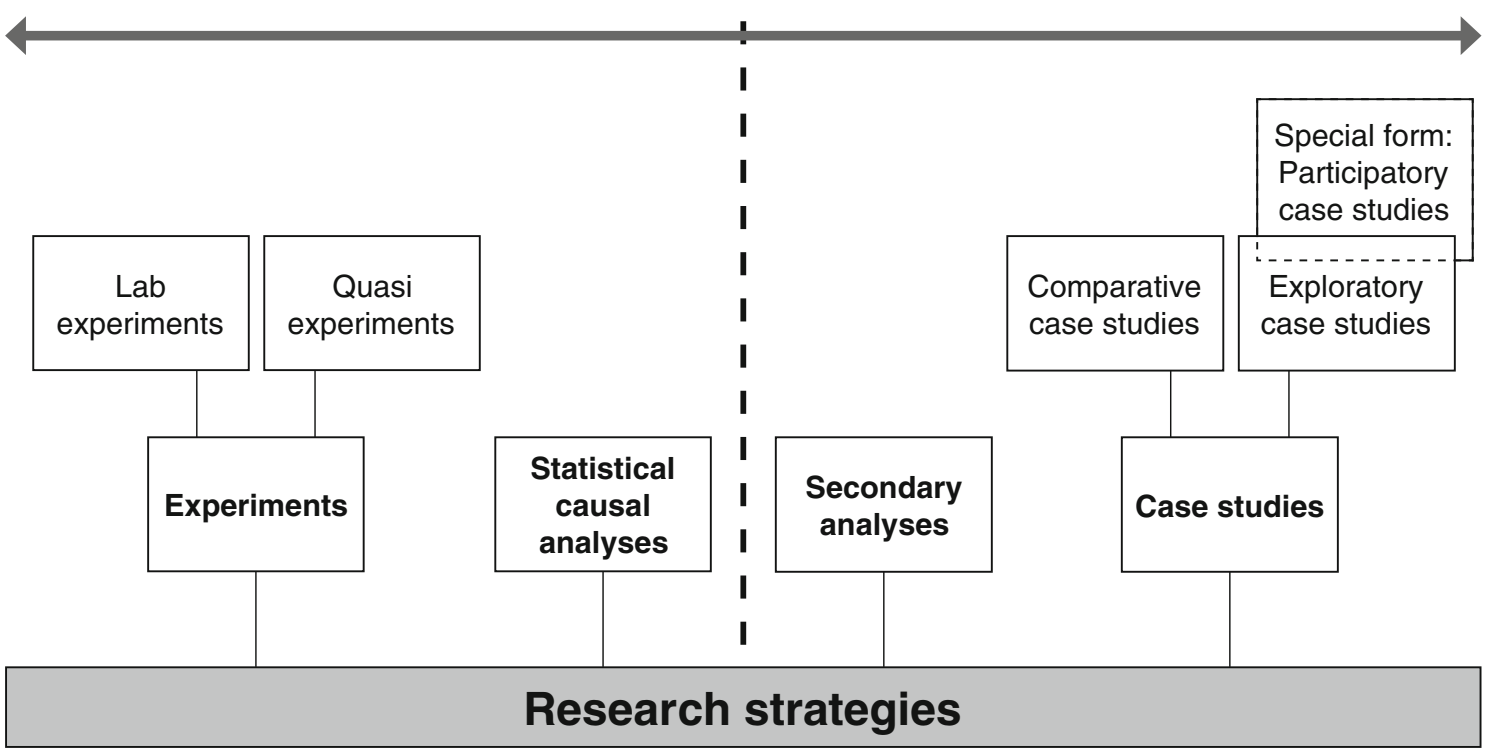

Fig. 1 Research strategies between experiment and case study

socio-scientific research and always applies to participatory practice research. Variable-manipulative methods are also based on the fact that all the empirical information that is relevant for scientific examination can be represented in the form of numerical information (i.e., in numbers). This prerequisite cannot be fulfilled by many socio-scientific objects of research either.

Rather, a variable-configurative research strategy, with the two most important method designs secondary analyses and case studies, is indicated.

Therefore, as long as

- the aim is to improve the multi-perspective, futureoriented and far-sighted understanding of complex and dynamic action systems in connection with the innovation of the method of influencing these systems

- and, considering the mutual influence of all constituent variables of the system (including the activities of the researcher), a clear definition of the so-called dependent and independent variables in not possible,

variable-configurative research strategies must be selected.

If a social researcher were to select a variable-manipulative research design (e.g., experiment) with the aim of participatory scientific assistance in a process of future-oriented and farsighted planning of a complex and dynamically changing action system, they would not be spared a reasonably grave accusation of wanting to tread a path which would never lead to the goal.
Variable-configurative research strategies can be roughly categorised into secondary analyses and case studies.

Secondary analyses, which are becoming more and more attractive considering the constant improvement in the archiving of empirical data in large databases, are by definition dependent on an already existing, well-developed relevant data basis.

Case study as a research strategy should primarily be used for social action contexts that have not been properly examined as yet. Even though one cannot deduce generalised statements from comparative case studies, it is possible to make socio-scientific statements, which transcend the specific conditions of two or more comparatively examined individual cases. However, this is done at the cost of the uniqueness of specific historical and local action constellations due to variable-control (which, although less rigid than in an experiment, is still necessary).

Exploratory case studies can be a research strategy most suitable for the objective and object of study in cases where the interaction between a variety of factors in, so far, less examined, complex and dynamically changing action contexts has to be analysed (especially with a far-sighted and innovationoriented view of future developments). The method design of exploratory cases studies can be considerably improved by using case study series (e.g., time series, etc.), among other things. A combination of empirical and hermeneutic methods proves to be useful in the case study design. 
A specific manifestation of the exploratory case study is the participatory case study, which is well suited for scientific assistance in the development of innovation processes in complex and dynamically changing action and/or practical contexts. This socio-scientific research design is based on the research logic of "participatory practice research", where the differences between Anglo-American and German concepts need to be taken into account. These differences will be briefly outlined in the following section.

\section{Traditions of practice research}

\section{Action research in Anglo-American regions}

The German social psychologist Kurt Lewin, who immigrated to the USA in 1933, is regarded as the founder of participatory social research. He started using the term "action research" only from 1944 and passed away before he could complete the planned fundamental work on this subject. However, Hart and Bond [5, p 24] point out that there is proof which suggests that the term "action research" was used by a few less known American social researchers much before Lewin. How the Lewin approach was further developed - by, for example, Fred Emery (Australia), Eric Trist (USA), Philippe Herbst (UK) or Einar Thorsrud (Norway) - is not discussed here in detail, since the present article is not intended to focus on a historical analysis of action research. Rapoport [6, p 44] names four concepts that influenced the development of the action research approach until the end of the 1960s:

- the "group-dynamic direction" going back to Lewin,

- the psychoanalytically founded "Tavistock projects",

- the "human relation movement" (in the context of applied anthropology), and

- "operation research".

In a more implicit way, the American concept of "pragmatism" (especially its socio-political and pedagogical variant as advocated by J. Dewey) also influences the theory and methodology of "action research" to a certain extent.

The approaches mentioned briefly above were seamlessly developed further in the Anglo-American regions from the 1970s. The corresponding discourses are available in two international peer-reviewed journals ("Action Research" and "Educational Action Research"). In this context, it is appropriate also to mention the important publications "Action Science" [7], "The SAGE Handbook of Action Research" [8], and the thematically relevant textbook by Hart/Bond [5].

The critical analysis of the Anglo-American approach of action research by the social sciences in German-speaking regions as outlined below was in turn only adopted to a limited extent in English-speaking regions.

\section{Participatory practice research in German-speaking regions}

The Anglo-American concepts of action research were not adopted in German-speaking regions before the end of the 1960s, but soon thereafter heavily criticised. The German sociologists Klüver and Krüger [9, p 88] regarded these action research approaches as "social technologies that are extremely subtle since they are directly application-oriented and can be applied arbitrarily". The German variant of "action research" developed in the 1970 s as a result of such critiques, forwarding a system-critical and emancipatory claim under the influence of the "student movement", the argumentation of the critical theory (in the context of the positivism dispute) as well as the Marxism-inspired critical psychology. In the German-speaking social sciences, the discourse about participatory variants of social research gained considerable significance in the 1970s. In addition to ideologically overloaded approaches [10] or in view of concepts that make exaggerated claims in terms of philosophy of science and scientific-political claims [11], publications with a methodological and research-methodological foundation also appeared in the pioneering phase of action research in German-speaking regions [12-16]. However, this unique approach to action research in German-speaking regions only blossomed between the beginning of the 1970s until the mid-1980s. As per Unger/Block/Wright [17, p 19], it was only between 1972 and 1982 that "400 publications on action research in German-speaking regions were released." This research approach lost its attraction no later than from the start of the 1990s.

In 1993, Altrichter and Gstettner [18] took stock of the action research debate in German-speaking regions in an article that is well worth reading. In this context, the reasons for the loss of importance of the critical action research were analysed, but also the impact on the research community were acknowledged. Today, research outcomes are labelled very rarely as "action research". However, important researchethical and research-methodical aspects of this research approach, such as social responsibility, participation, selfevaluation or cooperation between science and practice, continue to be practised under the name of "(participatory) practice research" in today's academia and are conceptually developed in several manifestations of empirical social research (e.g. in evaluation research, innovation research or in participatory futures research). "Unlike the debate about the action research of the 1970s, the discussion about this term is more pragmatic and less politically motivated", so Unger et al. [17, p 25]. Thus, Hug/Poscheschnik rightly call "action research" a specific manifestation of empirical social research in their extremely interesting textbook $[19, p$ 79]. The primary specification is that the "objective is not only to acquire knowledge" but also to contribute "to the solution of a concrete practical problem" 
(ibid.). As with Kurt Lewin, it is no longer as much about a new or revolutionary type of social research as, based on scientifically founded accompanying research, about the desire to participate in the process of social innovation. "The mere writing of books is too little for this form of research" [19, p 79].

This rational and pragmatic understanding of participatory practice research as it is practised in German-speaking regions today is described in this article as well as in several other publications [17, 20-22].

Reconciliation of practice research in German-speaking and Anglo-American regions

A reconciliation of the practice research discourse in Germanspeaking regions and the extremely vivid Anglo-American action research discourse is both linked to the above described development as well as to the intensified internationalisation of the academia over the past two decades. However, when taking this reconciliation process further-something that is fundamentally preferable - the tradition of an explicit foundation of research in terms of philosophy of science, even practice research, which is more developed in the social sciences practised by German-speaking regions, should not be sacrificed for the sake of the occasionally too pragmatic tradition of action research. In participatory practice research, it is important to explain - in terms of philosophy of sciencethe knowledge-generating dynamics of the communication between researchers and practitioners.

The various schools of thought, in terms of philosophy of science, are not only concerned with the possibilities and methods of the scientific understanding of "reality" but also with interfaces or links between the practice of the researchers and that of the research objects. Thus, the static variant of the mere communication of research results to practice is predominant in the schools of thought of critical rationalism and neopositivism. This is because according to such research logic, the "usage context" no longer falls within the scope of research.

Participatory social scientists in German-speaking regions are strongly advised to get involved in international networks of participatory practice research based on their research traditions. In this context, it must be noted that topics such as "community participation", "community-based participatory research" and "participatory action research", which were considered extremely important in the prime age of action research even in German-speaking regions, constitute "growing research fields which continue to be of increasing international significance" in the Anglo-American regions today [17, $\mathrm{p}$ 7]. The author of this article considers the connection between participatory practice research and futures research particularly productive.

\section{Participatory futures research}

Participatory futures research ${ }^{1}$ is understood as a specifically future-oriented manifestation of participatory practice research. As a matter of fact, it would be of historical interest to examine the parallels between socio-critical approaches and approaches that are oriented to emancipatory "shaping of the future" in futures research in the 1970s in German-speaking regions on the one hand $[2, \mathrm{p} 8]$ and the contemporary developments of action research in German-speaking regions on the other. This challenge, however, cannot be tackled in this article.

The function of practice-oriented futures research (even when it is not of a participatory nature) is both the provision of scientifically-founded knowledge about plausible future developments ("futures") in project-relevant conditions as well as the development of action-theoretically founded, innovative implementation strategies in the conflict between the current (historical) ACTUAL status and the future TARGET status.

Participatory futures research in the conflict between research and practice

In case of participatory futures research, the above-mentioned functions are fulfilled in the form of discursive participation of the researchers in the processes of far-sighted planning of improvements in the living conditions and/or in the quality of life in the respective social field. Participatory practice research in general and participatory futures research in particular are always characterised in two ways: as a theory-based far-sighted study of future and innovative practice on the one hand and practice-oriented (accompanying) research which claims to be far-sighted on the other.

The practical part of participatory futures research is clearly the far-sighted and participatory planning (as well as the model-based implementation to some extent) of improvements in the living conditions and/or in the quality of life in the respective social field.

The function and importance of the research part of participatory futures research can be summarised as follows: In view of the scientific system, the research part of participatory futures research constitutes the provision of feedback of those research results that have been acquired in a participatory manner as part of the scientific assistance in projects of future-oriented practice development. These research results can be integrated into the social sub-system of science that generally aims at acquiring new and theory-based knowledge and can thus contribute to progress in knowledge. In view of the process of "participatory change" within the scope of

\footnotetext{
${ }^{1}$ For the latest status of the theory and methodology of futures research, refer to the anthology published by Popp [23].
} 
accompanying research in future-oriented development projects, the research part constitutes the provision of scientific knowledge. This discursive transfer of knowledge aims to develop scientifically based innovative practice in the sense of a change from within that is brought about as a result of the discourse.

The basis for the success of such a participatory-changing procedure is to create and maintain a future and innovation oriented dialogue between the representatives of the scientific system on the one hand and the persons and groups in the practice system that aims at improving social or communicative, institutional and spatial-material conditions on the other hand.

By deciding to participate in a future-oriented planning and shaping process in a concrete social field, the participatory (futures) researcher cannot bypass questions of power hierarchies. While in case of variable-manipulative research strategies (e.g. in case of quasi experiments) these issues have already been methodically resolved in order to facilitate a distanced research attitude even before the researcher comes into the picture, the participatory and variable-configuratively oriented researcher has to consciously expose themselves to the complicated interactive dynamics of defining role and position under "natural" conditions. In this situation, the researcher can do nothing else but legitimise their "claims to power" (providing suggestions; offering methods, action and/or strategy recommendations, etc.).

Sensitive handling of data in the context of participatory futures research

The problem areas in the conflict between research method and research ethics, which have been discussed above, also include sensitive handling of data: Data material, most of which has been obtained in the participatory research process, cannot be used randomly and is, during the course of the project, primarily used only in the specific context of the respective innovation process for the purpose of action orientation, action preparation and action reflection. This sensitive claim to data usage does not stand in the way of the provision of data material, which can be justified before the practitioners and project addressees participating in this future-oriented development process, to the scientific system (mostly after the respective project is complete). In many cases however, the published output of projects of participatory (futures) research is only based on selected problems and has to be clarified with the practitioners participating in the respective project.

In principle, a participatory futures research that aims at being taken seriously in the scientific community should, in addition to its contribution towards future oriented and farsighted solutions of concrete practice-related problems, publish as many of its research results as possible. While the discourse on the necessarily sensitive handling of research data in view of practice-oriented research in the public welfare sector acting in public interest is mostly carried out with research-ethical justification arguments, the comparable discourse in companies that strive for commercial profit is mostly reduced to the legal clarification of usage rights.

Participatory futures research and the dual need to prove legitimisation

If the scientific system is one pole of participatory (futures) research, the practice fields that are characterised by the pragmatic logic of everyday life are the other pole. Being on the "cross-border", the participatory researcher inevitably gets caught in the sphere of influence of both interaction systems. This also gives rise to the dual need to prove legitimisation: before the scientific system in view of fulfilling the content and form related quality factors of scientific work (see further below in this article); and before the respective practice field in view of the practical usefulness of theory-guided recommendations.

While all variable-manipulative methods of field research and many manifestations of the variable-configurative research strategy (e.g., secondary analyses, comparative case studies, etc.) attempt to exclude the "self-reinforcing tendency of interactive processes" [24, p 305] from the research process through standardisation of research processes as well as through exclusion (which reduces the research process to a falsification of hypothesis) of the usage context, the participatory practice researcher has to consciously expose themselves to the interactive dynamics of defining role and position under "natural" conditions. ${ }^{2}$ These indications suggest that participatory research, in addition to the methodological, researchmethodical and discipline-specific knowledge and competencies that are essential for any scientific work, demands extremely well-developed communicative competency, and to some extent even self-reflexive competency, from the researcher. Psychoanalytically oriented authors like Horn [26] or Schülein [24] discussed this problem many years ago.

Participatory (futures) research not only aims at the analysis but also at the future-oriented modification and/or improvement of the "object of research". Unlike the somewhat naive, practice-transfiguring research understanding of the action research of the 1970s, the modern socio-scientific practice research assumes that the actions systems of research on the one hand and practice (which is not rooted in the scientific system) on the other hand are characterised by structurally different interests and action and success logics. The discourse between representatives of research and representatives of practice can succeed only if both sides recognise and accept the differences described in brief above. The participation of researchers in future-oriented development processes in a

\footnotetext{
${ }^{2}$ This fact has been known for decades, see [25, p 95].
} 
selected practice field is productive for research as well as for practice only if the specifics of this discourse are reflected and communicated through the interface (or rather the link) between research and practice in a methodically correct manner.

Based on the motto "less is more", the possibility of finding a way to overcome this difficult challenge will increase if the researcher resists all temptations to participate too arbitrarily in the practical tasks of shaping the future and consequently submits themselves, as per their competency, to scientific service for practice (that would shape the future). The "moment of distance" [21, p. 15] can be justified not only in a technical and group-dynamic manner but also in a psycho-hygienic manner.

Scientifically founded discourse between practice and research

The central communication forum of a theory-practice network that is constituted in a project context of participatory research is the discourse between the practitioners and researchers participating in the particular project.

The practical-methodical exertion of influence on the concrete social and/or institutional and spatial-material conditions in the respective action field depends on specific, commonly defined and - in as good a way as possible - scientifically founded development objectives that are oriented to the needs of the respective addressees and practitioners concerned as well as to the corresponding social need. Achieving these objectives, i.e., being successful (as a result of influencing socio-cultural and/or psycho-social conditions), also depends on the realistic estimation of the scope of action which is process-analytically and condition-analytically investigated. In projects related to participatory futures research, these multifactorial analyses are basically related to the far-sighted creation of realistic innovation possibilities in medium-term planning perspectives.

Participatory futures research is so productive especially in view of the scientific assistance in innovative change processes because this research design has been structured as a constant learning process and thereby makes it possible to deal with project-relevant factors in a flexible analytical-farsighted and active-planned manner. It is because of this flexibility that this specific type of case study requires precise documentation of not just the respective scientificallyassisted, practice-oriented planning processes but also of the research-methodical aspects of the case study itself (e.g., decisions about creating specific new data links, reasons for the possible change in planned research steps, unexpected or perhaps even critical developments, etc.).

\section{Quality factors of participatory (futures) research}

The quality factors developed for verifying the reliability and validity of variable-manipulative research processes are much too easily applied to all research methods, even to the variableconfigurative research methods, in many textbooks of empirical social research. These factors, however, are applicable to only a very limited set of conditions and objectives of many manifestations of socio-scientific research, including participatory practice research as well. But this limitation should not be the reason for not verifying reliability and validity at all. The challenge is the systematic reformulation of the quality factors that are applicable to participatory practice research and/or participatory futures research. However, there is no such concept at present and it cannot be presented in this article either. The following section aims at showing only some of the aspects of this research-methodical quality discourse.

\section{Reliability}

Reliability in terms of the reproducibility of results under the same inter-subjective conditions is naturally neither possible nor intended in variable-configurative research strategies in general and in participatory (futures) research in particular. In the critical discourse of the scientific community, this occasionally leads to the condemnation of participatory research strategies as being "unscientific" from the point of view of researchers who assume the existence of a set of rules applicable to all manifestations of research.

The aggressiveness with which many of these critiques are presented suggests that such conflicts are not a criticalacademic discourse that strives for the progress of science and research but rather a serious competition for "applied research" in the rapidly developing market.

\section{Validity}

Validity is always related to the plausibility of the examination results in view of the project and/or object relevant theories and/or theorems accepted in the scientific community.

Moreover, it should also be examined whether research processes (including the process of data documentation and the communicative-didactic method of communicating research results to practitioners) are implemented in a methodically correct manner, even though the quality of the research methodology can be assessed not on the basis of generally applicable factors but only with respect to whether the applied research strategy, in our case the variable-configurative and participatory strategy, is suitable for the research objective or not.

The short (and provisional) discourse about quality factors for participatory (futures) research mentioned above can be summarised as follows: There is no set of rules that can be used for quality checking across all manifestations of research. Factors such as reliability and validity must only be determined by taking the research objective and the object of 
research into account. The factors for high-quality research in the context of the diverse research strategies must incorporate plausible statements about objectivity and subjectivity. The degree of objectivity and subjectivity should be as defined below:

- as much objectivity (in terms of transparency, traceability, control, etc.) as is possible considering the research objective and the object of research,

- as much subjectivity (in terms of taking into account the "subjective factor" as well as the communication and learning process of all those who are involved in the research process) as is necessary regarding the research objective and the object of research.

\section{Methodology of future-oriented and participatory practice research}

On the basis of the methodologically founded concept of participatory, socio-scientific (futures) research that has been presented so far, we can arrive at some specific reflections about the methodology of this specific research strategy.

Scientific data collection during the course of future-oriented planning and development processes

With the help of case studies from the category of participatory futures research, it is possible to trace the course of a (future-oriented) project or perhaps even of a series of projects. At the same time, it is also possible to shed light upon the interplay of a variety of factors. As is generally known, knowledge and information about the respective object of research are acquired in close connection with the futureoriented course of practice. Data acquired in this manner includes empirical evaluation material from the respective project context (e.g., analysis of future-oriented needs and/or requirements, results of future-oriented workshops or conferences, etc.) as well as knowledge, based on which or in comparison with which project-oriented evaluation and empirical data can be assessed or interpreted in a theory-guided manner (e.g., data obtained from the analysis of literature, theoretical knowledge, everyday knowledge and/or corporate know-how of the practitioners involved in the action process, etc.).

When applying empirical and hermeneutic methods of socio-scientific work, it must not be forgotten that none of the research methods are scientific "inventions". They originate from everyday life and are mere improvements and/or clarifications of day-to-day actions (questioning, observing, comprehending, interpreting, describing, measuring, comparing, etc.). The author of the present article holds the wellfounded opinion that, in principle, both in futures research and in participatory practice research (action research) all known and tried-and-tested empirical and hermeneutic research methods from the area of the "variable-configurative research strategy" (see above) can be used. It is futile seeking for an "independent" methodology of futures research or action research [2, p 21].

With regard to all manifestations of participatory research, a clear distinction should be made between research methods and intervention methods capable of changing current practice (including methods of moderation, activation and promotion of communication).

Notes on splitting the research process into phases

In connection with the processes of participatory futures research, it should be taken into account that the research part as well as the practice part naturally bring about changes in the conditions to be examined, resulting in a modified ACTUAL status after every research phase which then forms the starting point for further critical reflection and/or for the planning and implementation of innovation processes. Participatory (futures) research is thus an iterative process. Each of these consecutive research and/or development phases constitutes the following research steps:

Phase 1: evaluation, critical-reflexive analysis and definition of the ACTUAL status

\section{Evaluation and description of the ACTUAL status}

The empirical (and project-history related) evaluation and/or empirical material (including the contexts of justification that are based on scientific and/or everyday theories and used in the respective project) should portray as accurate a picture of the current development status of the respective examined practice context as possible. After the evaluation process is complete, the documentation material in question must be discussed, and perhaps modified, by researchers and practitioners together.

\section{Critical-reflexive analysis of the ACTUAL status}

The researchers consolidate theory-guided knowledge, based on which or in comparison with which the respective practiceoriented evaluation and empirical data was or is criticallyreflexively interpreted or analysed.

\section{Discursive evaluation of the ACTUAL status}

After this consolidation of knowledge, a critical-reflexive evaluation and definition of the ACTUAL status occurs as part of the discourse between researchers and practitioners. 
Phase 2: critical-reflexive analysis and definition of the TARGET status

\section{Plausible futures}

As long as researchers who assist in projects possess adequate, scientifically founded know-how about the respective fieldspecific development tendencies, it is possible to deduce quite a large number of plausible future developments or "futures" from the critical-reflexive evaluation of the ACTUAL status of the examined practice context and perhaps to portray them in the form of scenarios.

\section{Desired future}

In the planning-oriented discourse with practitioners assisting in the respective project context, the subset of desired and feasible innovations, which is relevant for concrete planning, is filtered out from the total number of plausible future developments (scenarios). The documentation of arguments and criteria that are relevant for taking a decision is incumbent on the researchers as part of the discourse process.

\section{Clarification and definition of objective}

As the next step, the respective project-relevant innovation objectives must, in close cooperation between researchers and practitioners, be clarified in as concrete and operationalised a manner as possible and then defined.

\section{Graphic description of the required TARGETstatus}

Subsequently, the development status of the respective project context which is to be expected at the end of the respective medium-term planning period should, in close cooperation between researchers and practitioners, be described graphically and in as much detail as possible.

\section{Phase 3: implementation planning}

In the conflict between the ACTUAL-TARGET comparison, the interventions needed for the innovation-oriented development from the ACTUAL status to the TARGET status are analysed action-theoretically and defined and planned in close cooperation with practitioners ("implementation planning").

Future-oriented research projects must, by definition, exclude the execution of planned intervention(s), i.e., in a stricter sense, exclude implementation (with the exception of the occasional, initial implementation steps).
Phase 4: process and product evaluation

Owing to this future-oriented perspective, process evaluation is limited to the phase of evaluating the ACTUAL status up to implementation planning, where the iterative character of the project development planned for the (medium-term) future should be taken into consideration to the extent required.

Product evaluation and/or impact analysis is therefore limited to implementation planning and/or at best to a (naturally speculative) assumption about the impacts.

Data structuring

The huge amount of data that is obtained at the most varied data levels during the course of participatory (futures) research projects constitutes a fundamental problem of this research approach.

Often enough, an incalculable number of "data graveyards" were and are created as a result of such R\&D projects. In addition to the obvious need to carefully consider what data is really necessary for the respective research context, structuring the data material that is accumulated during the project in a manner that is both practical and suitable to the object of research becomes absolutely essential.

The instruments for data structuring, whose features must be conceived in the initial phase of a research project and further developed during the course of the project, are related to the analysis of innovation processes on the one hand and the analysis of the conditions system (of the ACTUAL and TARGET status) on the other.

Due to space constraints, these important researchtechnical problems can only be touched upon briefly here.

\section{Concluding remarks}

The success of participatory (futures) research depends greatly on the professional attitude of researchers. To achieve this, the self-conception of a researcher regarding their relation to practice should be explained in terms of philosophy of science. Furthermore, participatory (futures) researchers must involve themselves in the discourse of the scientific community. Among other things, this dialogue - obviously also with scientists who represent different methodological positionsshould relate to the following criteria that have been discussed in detail in this article:

- Disclosure of the methodological and methodical claims.

- Definition of specific quality factors for variableconfigurative research strategies, i.e., participatory and future-oriented research strategies in this case. In this context, the specifics of the communicative-participationoriented framework and of the foresighted, future- 
oriented character of the research objectives and objects of research should be disclosed.

- In the attempt to comprehend a research process, it is absolutely essential to have as unadorned (and selfcritical) a representation of the development of the respective research project as possible.

- It is also absolutely essential to provide data material or object and action-theoretic knowledge and theorems, all of which can be justified against the concrete practice field, to the scientific system. Fundamentally, research reports must also contain a short summary of data that has not been published at the request of the practitioner-including the relevant reasons for its exclusion.

- Fundamentally, the limited range of activities of participatory (futures) research must be assessed realistically: In addition to the essential reflection on the strengths and weaknesses of the case-specific and variableconfigurative research design, it is important to consider in case of participatory research that this research approach is suitable exclusively for small and manageable fields. This is because participatory (futures) research concentrates on the constant personal communication between researchers and practitioners.

In participatory practice research in general and in participatory futures research in particular, there is a range of manifestations that do not even fulfil the minimum criteria for research. These are rather services that are better described as "consulting" (futures consulting, innovation consulting, practice consulting, coaching, supervision, etc.) in terms of a technically more suitable and true product declaration. Thus, the function name "research" should not be used until at least the criteria for research briefly described above are fulfilled.

Open Access This article is distributed under the terms of the Creative Commons Attribution License which permits any use, distribution, and reproduction in any medium, provided the original author(s) and the source are credited.

\section{References}

1. De Haan G (2012) Der Masterstudiengang "Zukunftsforschung" an der Freien Universität Berlin: Genese und Kontext. In: Popp R (ed) Zukunft und Wissenschaft. Wege und Irrwege der Zukunftsforschung. Springer, Berlin-Heidelberg, pp 25-33

2. Popp R (2012) Zukunftsforschung auf dem Prüfstand. In: Popp R (ed) Zukunft und Wissenschaft. Wege und Irrwege der Zukunftsforschung. Springer, Berlin-Heidelberg, pp 1-24

3. Fink A, Siebe A (2006) Handbuch Zukunftsmanagement. Werkzeuge der strategischen Planung und Früherkennung. Campus, Frankfurt a.M

4. Schaffer H (2002) Empirische Sozialforschung für die Soziale Arbeit. Lambertus, Freiburg i. B
5. Hart E, Bond M (1995) Action research for health and social care. A guide to practice. Open University Press, Buckingham. German Version: Hart E, Bond M (2001) Aktionsforschung. Handbuch für Pflege-, Gesundheits- und Sozialberufe. H. Huber, Bern

6. Rapoport RN (1972) Drei Probleme der Aktionsforschung. Gruppendynamik 1/1972

7. Argyris C, Putnam R, Smith DM (1987) Action science. Concepts, methods and skills for research and intervention. Jossey-Bass, San Francisco

8. Reason P, Bradbury H (2007) The SAGE handbook of action research: participatory inquiry, 2nd edn. Sage, Thousand Oaks

9. Klüver J, Krüger H (1972) Aktionsforschung und soziologische Theorien. Wissenschaftstheoretische Überlegungen zum Erkenntnisinteresse in der Aktionsforschung. In: Haag $\mathrm{F}$ et al (eds) Aktionsforschung. Forschungsstrategien, forschungsfelder, forschungspläne. Juventa Paperback, Munich

10. Fuchs W (1970) Empirische Sozialforschung als politische Aktion. Soziale Welt $/ 1$

11. Moser H (1978) Aktionsforschung als kritische Theorie der Sozialwissenschaften. Kösel, Munich

12. Heinze T, Müller E, Stickelmann B, Zinnecker J (1975) Handlungsforschung im pädagogischen Feld. Juventa Paperback, Munich

13. Horn K (1979) Aktionsforschung. Balanceakt ohne Netz? Methodische Kommentare. Syndikat, Frankfurt a.M

14. Merz G (1985) Konturen einer neuen Aktionsforschung. Wissenschaftstheoretische und relevanzkritische Reflexionen im Blick auf die Pädagogik. Lang, Frankfurt a. M

15. Popp R (1985) Freizeitplanung als aktivierende Stadtteilarbeit. Vol. 3 : Handlungsorientierte Evaluation partizipativer Planungsprozesse im Grenzraum zwischen Sozial- bzw. Freizeitpädagogik und Stadtplanung. Methodologische und methodische Grundlegung. Österreichische Gesellschaft für Familie und Freizeit, Salzburg

16. Schneider U (1980) Sozialwissenschaftliche Methodenkrise und Handlungsforschung. Campus, Frankfurt a.M

17. Unger H, Block M, Wright $M$ (2007) Aktionsforschung im deutschsprachigen Raum. Zur Geschichte und Aktualität eines kontroversen Ansatzes aus Public Health Sicht. WZB, Berlin

18. Altrichter H, Gstettner P (1993) Aktionsforschung-ein abgeschlossenes Kapitel in der Geschichte der deutschen Sozialwissenschaft? Sozialwissenschaftliche Literatur Rundschau 26:67-83

19. Hug T, Poscheschnik G (2010) Empirisch Forschen. Über die Planung und Umsetzung von Projekten im Studium. UVK/ Huter\&Roth, Konstanz et al.

20. Altrichter H, Feindt A (2004) Handlungs- und Praxisforschung. In: Helsper W, Böhme J (eds) Handbuch der Schulforschung. Springer, Wiesbaden

21. Moser H (1995) Grundlagen der Praxisforschung. Lambertus, Freiburg i.B

22. Moser H (2008) Instrumentenkoffer für die Praxisforschung. Eine Einführung. Lambertus, Zürich

23. Popp R (ed) (2012) Zukunft und Wissenschaft. Wege und Irrwege der Zukunftsforschung. Springer, Berlin

24. Schülein J (1979) Aktionsforschung als soziale Praxis. Voraussetzungen und Probleme alternativer Sozialwissenschaft. In: Horn K (ed) Aktionsforschung. Balanceakt ohne Netz? Syndikat, Frankfurt a.M

25. Anhut R, Kroner B (1982) Macht und Ohnmacht im Experiment (Teil II). Psychologie und Gesellschaftskritik 1:95

26. Horn K (1979) Zur Bedeutung psychoanalytischer 'Technik'. Hinweise für eine kritische Sozialwissenschaft. In: Horn K (ed) Aktionsforschung. Balanceakt ohne Netz? Syndikat, Frankfurt a.M 